Pacific Journal of Mathematics

SEMIGROUPS WITH IDENTITY ON PLANO CONTINUA 


\title{
SEMIGROUPS WITH IDENTITY ON PEANO CONTINUA
}

\author{
W. WiLEY WILLIAMS
}

\begin{abstract}
A continuum is cell-cyclic if every cyclic element is a finite dimensional cell. We show that any finite dimensional cell-cyclic Peano continuum $X$ admits a commutative semigroup with zero and identity, and apply this to show that if $X$ is also homogeneous it is a point.
\end{abstract}

In [12] we showed that each cell-cyclic Peano continuum (locally connected metric continuum every cyclic element of which is a finite dimensional cell) $X$ admits a semilattice (commutative idempotent topological semigroup). We now extend this result to show that $X$ admits a commutative semigroup with identity and zero, and then apply this to homogeneous continua. Our extension is a partial answer to a question first raised by R. J. Koch in [6].

A semilattice is also a partially ordered Hausdorff topological space in which every two elements have a greatest lower bound and the function $(x, y) \rightarrow g l b\{x, y\}$ is continuous. For $A \subset S$, let $L(A)=\{z: z \leqq x$ for some $x \in A\}$ and $M(A)=\{y: x \leqq y$ for some $x \in A\}$. A set $A$ is increasing if $M(A)=A$. An arc chain is a totally ordered subset of a semilattice whose underlying space is an arc. We reserve $I$ for the unit interval under min multiplication, and $T$ for the quotient semilattice obtained by identifying $(0,0)$ and $(1,0)$ in $\{0,1\} \times I$. Note that $I^{n}$ and $T^{n}$, under coordinatewise multiplication, are semilattices with identity on the $n$-cell, with zero in the boundary and interior respectively.

Let $X$ be a cell-cyclic Peano continuum. We use the cyclic element notation and results of Whyburn [10] and Kuratowski and Whyburn [8], slightly modified in the following way. In $X$ we say a set $A$ separates $a$ and $b$ if each arc from $a$ to $b$ meets $A . \quad C(p, q)$ denotes the cyclic chain from $p$ to $q$ and is $\{x \in X \mid$ some arc from $p$ to $q$ contains $x$. An subcontinuum $A$ of $X$ is an $A$-set if each arc in $X$ having end points in $A$ is contained in $A$. Cyclic elements and cyclic chains are $A$-sets. Given a point $x$ and an $A$-set $A$, if $x \notin A$ there is a unique element $y \in A$ such that $y$ separates each element of $A$ from $x$. Denote this $y$ by $P(A, x)$. If $x \in A$ set $P(A, x)=x$. Then for a fixed $A$-set $A$ the function $x \rightarrow P(A, x)$ is a monotone retraction of $X$ onto $A$ mapping $X \backslash A$ into $\operatorname{Fr}(A)=\left\{x \in A \mid x \notin D^{0}\right.$ for any cyclic element $D$ of $A\} \cup\{$ cut points of $A\}$. A set $M$ is nodal in $X$ if $M \cap(X \backslash M)^{*}$ contains at most one point. A point is an end point of $X$ if it has a basis of neighborhoods having one point 
boundary. A node of $X$ is either (i) a true cyclic element which is a nodal set or (ii) an endpoint. $\operatorname{By} \operatorname{Com}(x, A)$ we mean the component of $x$ in $A$. The interior of $A$ is denoted by $A^{0}$.

\section{Preliminary results.}

Theorem 1.1. [12]. Any cell-cyclic Peano continuum admits the structure of a semilattice.

We note that in the proof of 1.1 given in [12], $I^{n}$ and $T^{n}$, as defined above, could have been used for the semilattice structures on the individual cyclic elements. Thus the structure may be so constructed that each cyclic element is a semilattice with identity; also the zero may be chosen to by any predetermined point.

The following is an unpublished result due to Phyrne Bacon. We include a proof for completeness.

THeOREM 1.2. Let $X$ be a compact semilattice and $C$ an arc chain containining 0 . If $\Pi_{C}$ is defined by $\Pi_{C}(x)=\sup \{a \in C \mid x \in M(a)\}$, then

(i) $\Pi_{C}$ is a homomorphism from $X$ onto $C$

(ii) $\Pi_{C}$ is continuous iff whenever $x, y \in C$ and $x<y$ then $y \in M(x)^{0}$.

Proof. $X$ compact implies $\Pi_{C}$ is well-defined. For (i), first note that $I_{C}$ is order preserving. Let $x, y \in X$ and suppose $\Pi_{C}(x) \leqq \Pi_{C}(y)$. Since $\Pi_{C}$ is order preserving we have $\Pi_{C}(x y) \leqq \Pi_{C}(x)$. If $\Pi_{C}(x y)<$ $\Pi_{C}(x)$, then there exists $z \in C$ such that $\Pi_{C}(x y)<z<\Pi_{C}(x)$. Thus $x \in M(z)$ and $x y \notin M(z)$. But $\Pi_{C}(x)<\Pi_{C}(y)$ and $x \in M(z)$ implies $y \in M(z)$. We conclude $x y \in M(z)$, a contradiction. Thus

$$
\Pi_{C}(x y)=\Pi_{C}(x)=\Pi_{C}(x) \Pi_{C}(y) .
$$

By symmetry, if $\Pi_{c}(y) \leqq \Pi_{C}(x)$ then the same conclusion is reached, and $\Pi_{C}$ is a homomorphism.

For (ii), suppose whenever $x, y \in C$ and $x<y$, then $y \in M(x)^{\circ}$. For each $x \in C$ define $V(x)=X \backslash M(x)$. Then each $V(x)$ is open, and we claim that $x<y$ implies $V(x)^{*} \subset V(y)$. First note that $M\left(M(x)^{\circ}\right)$ is open by the continuity of multiplication, contains $M(x)^{\circ}$, and is contained in $M(x)$. Thus $M\left(M(x)^{\circ}\right)=M(x)^{\circ}$, and $M(x)^{\circ}$ is increasing. So if $x<y$, then $y \in M(x)^{\circ}$, and $M(y) \subseteq M\left(M(x)^{\circ}\right)=M(x)^{\circ}$. Thus $V(y)=X \backslash M(y)$ contains $X \backslash M(x)^{\circ}=[X \backslash M(x)]^{*}=V(x)^{*}$. Since $C$ is an arc chain, inf $\{a \in C \mid x \in V(a)\}=\sup \{a \in C \mid x \in M(a)\}=\Pi_{C}(x)$. Thus a proof like that for Urysohn's lemma [3] shows $\Pi_{C}$ is continuous. This completes the proof. 
It is implicit in results of Lawson [9] that if $X$ is a semilattice on a finite dimensional Peano continuum, then (i) each point of $X$ lies on an arc chain $C$ containing 0 , and (ii) if $x<y$ in $C$, then $y \in M(x)^{\circ}$. We conclude

Corollary 1.3. Each point of a finite dimensional Peano continuum $X$ lies on an arc chain $C$ containing 0 and there is a homomorphic retraction of $X$ onto $C$.

THEOREM 1.4. Any finite dimensional cell-cyclic chain $C(p, q)$ admits a semilattice with identity. Moreover, if $q \in \operatorname{Fr}(C(p, q))$ then $q$ can be chosen to be the identity.

Proof. Note that the true cyclic elements of $C(p, q)$ form a countable collection $\left\{D_{i}\right\}$. We consider two cases:

Case 1. Some true cyclic element $D_{0}$ of $C(p, q)$ contains $q$. Then $D_{0}$ admits a semilattice structure with zero $a=P(D, p) \neq q$ and identity $e$. Moreover if $q \in \operatorname{Fr}(C(p, q))$ then $q \in \operatorname{Fr}\left(D_{0}\right)$, so we may choose $e=q$. By 1.1, $C(p, a)$ admits a semilattice in which each cyclic element $D_{i}$ is a semilattice with identity $e_{i}$ and zero $P\left(D_{i}, p\right)$. In each $D_{i}$ there is an arc chain $T_{i}$ from $e_{i}$ to $b_{i}=P\left(D_{i}, q\right)$ and also an arc chain $T_{0}$ in $D_{0}$ from $e$ to $a$ and a homomorphism $h: D_{0} \rightarrow T_{0}$ which is a retraction. Let $f_{i}: T_{0} \rightarrow T_{i}$ be an onto homomorphism for each $i$. Now define a semilattice structure ${ }^{*}$ on $C(p, q)$ to agree with those on $C(p, a)$ and $D_{0}$ and such that if $x \in C(p, a)$ and $y \in D$ then

$$
x * y=y * x=\left\{\begin{array}{l}
x \text { if } x \text { is a cut point of } C(p, a) \\
x \cdot f_{i}(h(y)) \text { if } x \in D_{i}
\end{array}\right.
$$

This obviously idempotent and commutative. Associativity and continuity follow since $h$ and $f_{i}$ are homomorphisms and continuous. Note that $e$ is an identity for *.

Case 2. $q$ is not in any true cyclic element of $C(p, q)$. Then there is a sequence $\left\{c_{i}\right\}$ of distinct cut points of $C(p, q)$ such that $\left\{c_{i}\right\} \rightarrow q$ and $c_{i+1}$ separates $c$ from $q$. This implies

$$
C(p, q) \backslash \bigcup_{i=1}^{\infty} C\left(c_{i}, c_{i+1}\right)=\{q\} .
$$

Endow each $C\left(c_{i}, c_{i+1}\right)$ with a semilattice structure as in 1.1 so that $c_{i}$ is the zero of $C\left(c_{i}, c_{i+1}\right)$ and each cyclic element $D_{j}$ is a semilattice with zero $P\left(D_{j}, p\right)$ and identity $e_{j}$, and let $T_{j}$ be a (possibly degenerate) 
are chain in $D_{j}$ from $e_{j}$ to $P\left(D_{j}, q\right)$. Let $S_{i}$ be an are chain in $C\left(c_{i}, c_{i+1}\right)$ from $c_{i}$ to $c_{i+1}$ and let $h_{i}: C\left(c_{i}, c_{i+1}\right) \rightarrow S_{i}$ be a homomorphism and retraction. For each $i, j \in Z^{+}$, let $f_{i, j}: S_{i} \rightarrow T_{j}$ be an onto homomorphism. Now define an operation $*$ on $C(p, q)$ to agree with that on each $C\left(c_{i}, c_{i+1}\right)$ and such that if $x \in C\left(c_{m}, c_{m+1}\right)$ and $y \in C\left(c_{n}, c_{n+1}\right)$ then

$$
y * x=x * y=\left\{\begin{array}{c}
x \text { if } x \text { is a cut point and } n=m+1 \\
x \text { if } n>m+1 \\
x f_{n, j}\left(h_{n}(y)\right) \text { if } x \text { is not a cut point } \\
\quad\left(\text { i.e., } x \in D_{j} \text { for some } j \in Z^{+}\right) \text {and } \\
n=m+1
\end{array}\right.
$$

Define $q$ to be an identity for $C(p, q)$.

This is obviously idempotent and commutative. The proof of associativity is similar to that in Case 1 except in the following case: Suppose $x \in C\left(c_{n}, c_{n+1}\right), y \in C\left(c_{n+1}, c_{n+2}\right)$ and $z \in C\left(c_{n+2}, c_{n+3}\right)$. If $x$ is a cut point, then $x * y * z=x$ in any order, and if $y$ is a cut point then $x * y * z=x * y$ in any order. If neither is a cut point then $x \in D_{z}$ and $y \in D_{k}$ for some true cyclic elements $D_{j}$ and $D_{k}$. So

$$
(x * y) * z=x * y=x f_{n+1, j}\left(h_{n+1}(y)\right) .
$$

Now $x *(y * z)=x *\left(y f_{n+2, k}\left(h_{n+2}(z)\right)=x f_{n+1, j}\left(h_{n+1}\left(y f_{n+2, k}\left(h_{n+2}(z)\right)\right)\right)\right.$. But $h_{n+1}\left(y f_{n+2, k}\left(h_{n+2}(z)\right)\right)=h_{n+1}(y) h_{n+1}\left(f_{n+2, k}\left(h_{n+2}(z)\right)\right)$ since $\mathrm{h}_{n+1}$ is a homomorphism. Also $h_{n+1}(y) \leqq P\left(D_{k}, q\right)=h_{n+1}\left(f_{n+2, k}\left(h_{n+2}(z)\right)\right)$ since $S_{n+1} \cap D_{k}$ is an arc chain with maximum element $P\left(D_{k}, q\right)$ and $T_{k}$ is an arc chain with minimum element $P\left(D_{k}, q\right)$. It follows that

$$
x *(y * z)=x f_{n+1, j}\left(h_{n+k}(y)\right)=x * y=(x * y) * z .
$$

Suppose $x_{n} \rightarrow x$ and $y_{n} \rightarrow y$. If $x \neq q \neq y$, then one can prove $x_{n} * y_{n} \rightarrow x y$ using the continuity of the functions $h_{i}$ and $f_{n, j}$ and the fact that the cyclic chains $C\left(c_{i}, c_{i+1}\right)$ meet only at cut points. If $x=q \neq y$ and $y \in C\left(c_{i}, c_{i+1}\right)$ then eventually $c_{i-1} \leqq y_{n} \leqq c_{i+2}$ and $c_{i+4} \leqq x_{n}$ so that $x_{n} * y_{n}=y_{n} \rightarrow y=x y$. If $x=q=y$ and if $W\left(x_{n}, y_{n}\right)$ denotes the smaller of $i$ and $j$ where $x_{n} \in C\left(c_{i}, c_{i+1}\right)$ and $y_{n} \in C\left(c_{j}, c_{j+1}\right)$ then $W\left(x_{n}, y_{n}\right) \rightarrow \infty$ as $n \rightarrow \infty$. Since $x_{n} * y_{n} \in C\left(c_{W\left(x_{n}, y_{n}\right)}, c_{W\left(x_{n}, y_{n}\right)+1}\right)$ and since $C(p, q)$ is locally connected we conclude that $x_{n} * y_{n} \rightarrow q=x y$. This completes the proof.

We note that in Case 2, if $c_{n+1}$ separates $x$ from $p$ and $c_{n}$ separates $y$ from $q$ then $x * y=y$.

\section{Ruled continua.}

Definition 2.1. Suppose $X$ is a topological space and $E \subseteq X$, 
$0 \in X$. Let $A=\{[0, e]: e \in E\}$ be a collection of arcs in $X$ satisfying: (i ) $X=U\{[0, e]: e \in E\}$.

(ii) $[0, e] \cap[0, f]$ is a proper subarc of each when $e$ and $f$ are distinct elements of $E$.

(iii) For each $e \in E$, there is a unique $[0, e] \in A$.

(iv) If $x_{\alpha} \rightarrow x$ then $\left[0, x_{\alpha}\right] \rightarrow[0, x]$ in the sense of lim sup-lim inf convergence.

Then $A$ is said to be a ruling of $X$ and $X$ is said to be a ruled space with zero 0 . The concept of a ruled space was introduced by Eberhart in his dissertation [4]. Spaces admitting a stronger type of ruling have been studied by Koch and McAuley [7]. We note that if $X$ is ruled then for each $x \in X$ there is a unique arc $[0, x]$ which is contained in every $[0, e]$ containing $x$.

Definition 2.2. A metric $d$ is radially convex with respect to a partial order $\leqq$ on $X$ if $x \leqq y, y \leqq z$ and $y \neq z$ imply $d(x, y)<$ $d(x, z)$.

Lemma 2.3. Let $X$ be a compact metric ruled space. Define $x \leqq y$ iff $x \in[0, y]$. Then $\leqq$ is a closed partial order on $X$. Moreover $X$ admits a metric radially convex with respect to this order, so that if $r \leqq d(0, e)$ there is a unique $x(r) \in[0, e]$ such that $d(0, x(r))=r$.

Proof. This is clearly a partial order; that it is closed follows from property iv) of ruled spaces. By a result of Carruth [2], X admits a metric radially convex with respect to this order. The lemma now follows.

THEOREM 2.4. Any cell-cyclic Peano continuum $X$ admits a ruling, and 0 may be chosen to be any point of $X$.

Proof. By 1.1, $X$ admits a semilattice with zero 0 chosen arbitrarily. As in the proof of 1.1 given in [12], for each true cyclic element $D$ of $X$ let $h_{D}$ denote the homeomorphism from $I^{n}$ or $T^{n}$ to $D$ used to define this semilattice. Set $E=\operatorname{Fr}(X) \backslash(\{$ cut points of $X\} U\{0\})$. For each $e \in E$ and each true cyclic element $D$ of $C(0, e)$ define $T(D, e)$ to be the image under $h_{D}$ of the straight line segment $\left[h_{D}^{-1}(P(D, 0)), h_{D}^{-1}(P(D, e))\right]$ in $I^{n}$ or $T^{n}$. Then define $[0, e]=(\cup\{T(D, e)$ : $D \in C(0, e)\}) \cup\{$ cut points of $C(0, e)\}$. Then $[0, e]$ is a metric, compact (since $C(0, e) \backslash[0, e]$ is open in $C(0, e)$ ) order dense chain in the semilattice $X$ and hence an arc. We now show the four conditions are satisfied. 
(i) $X=U\{0, e]: e \in E\}$. If $x \in X \backslash E$ then $x$ is either an interior point of some cyclic element $D$ of $X$ or a cut point of $X$. If $x$ is an interior point of $D$ then $x \in h_{D}\left(h_{D}^{-1}\left(P(D, 0), h_{D}^{-1}(e)\right]\right)$ for some $e \in \operatorname{Fr}(D)$. If $e \in E$ then $x \in T(D, e) \subseteq[0, e]$. If $e \in E$ then choosing an end element $e^{\prime}$ of a component of $X \backslash\{e\}$ other than the one containing $0, x \in\left[0, e^{\prime}\right]$

(ii) and (iii) are clear

(iv) If $e_{\alpha} \rightarrow e$, then $\left[0, e_{\alpha}\right] \rightarrow[0, e]$. This follows from the fact that $\left[0, e_{\alpha}\right] \subseteq L\left(e_{\alpha}\right)$ and from techniques like those in [12]. We omit the details.

THeorem 2.5. Any cell-cyclic Peano continuum with a nodal cyclic element admits a commutative semigroup with identity and zero.

Proof. Let $X$ be a cell cyclic Peano continuum and suppose $X=C \cup D$, where $C \cap D=\{0\}$ and $D$ is a true cyclic element. Then $C$ is a cell-cyclic Peano continuum and hence admits a ruling $A=\{[0, e]: e \in E\}$ with zero 0 and a radially convex metric. Let $h$ be a homeomorphism from $I^{n}$ or $T^{n}$ to $D$, depending on whether 0 is in the boundary or interior of $D$, and define a semilattice with identity $e$ on $D$ using $h$. Then there is in $D$ an arc chain $S$ from 0 to $e$ and a retraction $f: D \rightarrow S$ which is a homomorphism. Moreover we may assume that $S$ is radially convex so that for $x, y \in S$, $d(0, x y)=\min \{d(0, x), d(0, y)\}$. Without loss of generality we may assume $d(0, e)$ is maximal among $\{d(0, x) \mid x \in X\}$. Now define a semigroup on $X$ by

$$
y * x=x * y=\left\{\begin{array}{l}
0 \text { if } x, y \in C \\
x y \text { if } x, y \in D \\
\text { The point in }[0, x] \text { of distance } r= \\
\text { min }\{d(0, x), d(0, f(y))\} \text { from } 0 \text { if } x \in C, y \in D .
\end{array}\right.
$$

Associativity is obvious in all cases except the following: Suppose $x \in C$ and $y, z \in D$. Then $(x * y) * z$ is the point in $[0, x]$ of distance $\min \{d(0, x), d(0, f(y)), d(0, f(z))\}$ from 0 , whereas $x *(y * z)$ is the point in $[0, x]$ of distance min $\{d(0, x), d(0, f(y, z))\}$ from 0 . But $d(0, f(y z))=$ $d(0, f(y) f(z))=\min \{d(0, f(y)), d(0, f(z))\}$ so $(x * y) * z=x *(y * z)$. Continuity follows from the properties of ruled spaces and the fact that $f$ is continuous. It is clear that $e$ is an identity and 0 a zero. This completes the proof.

We conjecture that any $X$ as in 2.5 admits a semilattice with identity. In fact, if $X$ can be embedded in a plane then $X$ can be embedded in a two-cell $N$ and ruled in such a way that $X \cap \operatorname{Fr}(N)$ is one of the ares ruling $X$. One can now apply a theorem from 
Eberhart's dissertation to show that $X$ admits a semilattice with identity.

III. Cell-cyclic Peano continua without a nodal cyclic element. The goal of this section is a result like 2.5 for finite dimensional cell-cyclic Peano continua without a nodal cyclic element.

Lemma 3.1. Let $X$ be a cell-cyclic Peano continuum. Then there exist two sequences $\left\{p_{i}\right\}$ and $\left\{q_{i}\right\}$ in $\operatorname{Fr}(X)$, with $p_{1}$ and $q_{1}$ chosen arbitrarily, such that

(i) If we set $H_{n}=\bigcup_{i=1}^{n} C\left(p_{i}, q_{i}\right)$, then for each $n>1$, $\left\{p_{n}\right\}=C\left(p_{n}, q_{n}\right) \cap H_{n-1}$

(ii) If we set $H=\bigcup_{n=1}^{\infty} H_{n}$, then each point of $X \backslash H$ is an end point of $X$, and so $H^{*}=X$.

(iii) The diameter of the components of $S \backslash H_{n}$ tends to 0 uniformly with $1 / n$.

Proof. This was proved by Whyburn ([10], p. 73) without the condition that $\left\{p_{i}\right\}$ and $\left\{q_{i}\right\}$ are in $\operatorname{Fr}(X)$. We show this condition can also be assumed. Whyburn's proof considers a dense sequence $\left\{r_{i}\right\}$ and sets $p_{1}=r_{1}, q_{1}=r_{2}$. Clearly these may be chosen arbitrarily in $\operatorname{Fr}(X)$. In Whyburn's proof, for $j>1 q_{j}$ is the $r_{i}$ of smallest index such that $r_{i} \notin H_{j-1}$ and $p_{j}=P\left(H_{j-1}, q_{j}\right)$. Thus $p_{j} \in \operatorname{Fr}(X)$. If $q_{j} \notin \operatorname{Fr}(X)$, then $q_{j}$ is an interior point of some true cyclic element $D$. Let $q_{j}^{\prime}$ be any point in $\operatorname{Fr}(D)$ other than $P\left(D, p_{j}\right)$. Then $C\left(p_{j}, q_{j}\right)=$ $C\left(p_{j}, q_{j}^{\prime}\right)$, so we may assume $q_{j} \in \operatorname{Fr}(X)$. The lemma follows.

Now let $X$ be a finite dimensional cell-cyclic Peano continuum without a nodal cyclic element. Then $X$ has at least 2 end points ([10], p. 77); let 0 and 1 denote end points of $X$. Let $\left\{p_{i}\right\},\left\{q_{i}\right\},\left\{H_{n}\right\}$, and $H$ be as described in 3.1, with $p_{1}=0, q_{1}=1$. Each $C\left(p_{i}, q_{i}\right)$ admits a semilattice with zero $p_{i}$ and identity $q_{i}$ by 1.3 . We now define inductively an algorithm for defining a semilattice with identity on $H$.

Let $\left\{c_{j}\right\}$ be the sequence of cut points of $C(0,1)$ converging to 1 such that $c_{j+1}$ separates $c_{j}$ from 1 used in 1.3 to define the semilattice on $C(0,1)$. Let $n_{1}$ be one more than the smallest $i$ such that $c_{i}$ separates $p_{2}$ from 1 in $X$. Set $Q_{1}=C\left(p_{2}, q_{2}\right), P_{1}=\left[\operatorname{Com}\left(1, C(0,1) \backslash\left\{c_{n_{1}}\right\}\right)\right]^{*}$, and $R_{1}=\left[\operatorname{Com}\left(0, C(0,1) \backslash\left\{c_{n_{1}}\right\}\right]^{*}\right.$. Let $T_{1}$ be an arc chain from $p_{2}$ to $q_{2}$ in $Q_{1}$ and $S_{1}$ be an arc chain from $c_{n_{1}}$ to 1 in $C(0,1)$. Let $f_{1}: S_{1} \rightarrow T_{1}$ be a continuous onto homomorphism such that $f_{1}^{-1}\left(q_{2}\right)=M\left(c_{n_{1}+1}\right) \cap S_{1}$, and let $h_{1}: P_{1} \rightarrow T_{1}$ be the continuous onto homomorphism obtained by composing $f_{1}$ and a homomorphic retraction $r_{1}$ of $C\left(c_{n_{1}}, 1\right)$ onto $S_{1}$. We now define a semilattice $*$ on $H_{2}=C\left(p_{1}, q_{1}\right) \cup C\left(p_{2}, q_{2}\right)=H_{1} \cup Q_{1}$ by 


$$
x * y=y * x=\left\{\begin{array}{l}
x y \text { if } x, y \in C(0,1)=P_{1} \cup R_{1} \text { or } x, y \in Q_{1} \\
x p_{2} \text { if } x \in R_{1}, y \in Q_{1} \\
h_{1}(x) y \text { if } x \in P_{1}, y \in Q_{1}
\end{array}\right.
$$

where juxtaposition means whichever of the previously defined operations on $H_{1}$ or $Q_{1}$ fits the context.

Associativity is clear in all cases except when $r \in R_{1}, \quad p \in P_{1}$, $q \in Q_{1}$. In this case $r *(p * q)=r *\left(h_{1}(p) q\right)=r p_{2}$, whereas

$$
(r * p) * q=(r p) p_{2}=r\left(p p_{2}\right)=r p_{2}
$$

by the note at the end of Section I. Continuity is easily checked since $P_{1}, Q_{1}$ and $R_{1}$ meet only at cut points of $X$. Note that any point in $C\left(c_{n_{2}+1}, 1\right)$ acts as an identity for any point in

$$
\text { [Com } \left.\left(0, H_{2} \backslash\left\{c_{n_{1}}\right\}\right)\right]^{*} \text {, }
$$

and 1 acts as an identity for all of $H_{2}$.

Suppose that a semilattice structure with zero 0 and identity 1 has been defined on $H_{k-1}$ so that the structure agrees with those on $C\left(P_{i}, q_{i}\right)$ for each $i \leqq k$. Also suppose $c_{n_{k-1}} \in\left\{c_{i}\right\}$ has been chosen so that any element of $\left[\mathrm{Com}\left(1, H_{k-1} \backslash\left\{c_{n_{k-1}+1}\right\}\right)\right]^{*}$ acts as an identity for any element $\left[\operatorname{Com}\left(0, H_{k-1} \backslash\left\{c_{n_{k-1}}\right\}\right)\right]^{*}$.

Let $n_{k}$ be one more than the smallest integer greater than $n_{k-1}$ such that $c_{n_{k}}$ separates $p_{k+1}$ from 1. Set $Q_{k}=C\left(p_{k+1}, q_{k+1}\right)$, $P_{k}=C\left(c_{n_{k}}, 1\right)=\left[\operatorname{Com}\left(1, H_{k} \backslash\left\{c_{n_{k}}\right\}\right)\right]^{*}$, and $R_{k}=\left[\operatorname{Com}\left(0, H_{k} \backslash\left\{c_{n_{k}}\right\}\right)\right]^{*}$. Let $T_{k}$ be an arc chain from $P_{k+1}$ to $q_{k+1}$ in $Q_{k}$ and $S_{k}=S_{1} \cap P_{k}$. Let $f_{k}: S_{k} \rightarrow T_{k}$ be a continuous onto homomorphism such that

$$
f_{k}^{-1}\left(q_{k+1}\right)=M\left(c_{n_{k}+1}\right) \cap S_{k}
$$

in $P_{k}$, and let $h_{k}: P_{k} \rightarrow T_{k}$ be a continuous onto homomorphism obtained by composing $f_{k}$ and the homomorphic retraction $r_{k}=r_{1} \mid P_{k}$ of $C\left(c_{n_{k}}, 1\right)=P_{k}$ onto $S_{k}$. We now define a semilattice $*$ with identity 1 on $H_{k}$ by

$$
x * y=y * x=\left\{\begin{array}{l}
x y \text { if } x, y \in H_{k-1} \text { or } x, y \in Q_{k} \\
x p_{k} \text { if } x \in R_{k}, y \in Q_{k} \\
h_{k}(x) y \text { if } x \in P_{k}, y \in Q_{k}
\end{array}\right.
$$

where juxtaposition means whichever of the previously defined operations on $H_{k}$ or $Q_{k}$ fits the context.

Again associativity is clear in all cases except when $r \in R_{k}$, $p \in P_{k}, \quad q \in Q_{k}$. In this case $r *(p * q)=r *\left(h_{k}(p) q\right)=r p_{k}$, whereas $(r * p) * q=(r p) p_{k}=r\left(p p_{k}\right)$ since the operation on $H_{k-1}$ is associative. But $p \in\left[\operatorname{Com}\left(1, H_{k-1} \backslash\left\{c_{n_{k-1}+1}\right\}\right)\right]^{*}$ and $p_{k} \in\left[\operatorname{Com}\left(0, H_{k-1} \backslash\left\{c_{n_{k-1}}\right\}\right)\right]^{*}$ so by hypothesis $p p_{k}=p_{k}$, and $r *(p * q)=(r * p) * q$. Continuity is again 
easily checked. Again any point in $\left[\operatorname{Com}\left(1, H_{k} \backslash\left\{c_{n_{k}+1}\right\}\right)\right]^{*}$ acts as an identity for any element [Com $\left.\left(0, H_{k} \backslash\left\{c_{n_{k}}\right\}\right)\right]^{*}$. By induction we have proved the following:

LEMMA 3.2. Each $H_{n}$ admits a semilattice with zero 0 and identity 1 so that the operations agree whenever possible.

LEMMA 3.3. The function $P\left(H_{n}, \cdot\right): H \rightarrow H_{n}$ is a retraction and a homomorphism for each $n$.

Proof. It has been previously noted that each $P\left(H_{n}, \cdot\right)$ is a retraction. To show that each is a homomorphism it suffices to show that the restriction of $P\left(H_{n}, \cdot\right)$ to $H_{n+1}$ is a homomorphism, since $P\left(H_{n}, \cdot\right)$ is the composition of this restriction and $P\left(H_{n+1}, \cdot\right)$. Let $x, y \in H_{n+1}=H_{n} \cup Q_{n}$. If $x, y \in Q_{n}$ then

$$
P\left(H_{n}, x\right) * P\left(H_{n}, y\right)=p_{n} * p_{n}=p_{n}=P\left(H_{n}, x * y\right)
$$

since $x * y \in Q_{n}$. If $x \in Q_{n}, y \in H_{n}$ then there are two cases. If $y \in P_{n}$ then $P\left(H_{n}, x\right) * P\left(H_{n}, y\right)=p_{n} * y=p_{n}$ since $p_{n} \in R_{n-1}$ by definition and any element of $P_{n}$ acts as an identity for any element of $R_{n-1}$. However $P\left(H_{n}, x * y\right)=P\left(H_{n}, x * h_{n}(y)\right)=p_{n}$ since $x * h_{n}(y) \in Q_{n}$. If $y \in R_{n}$ then $P\left(H_{n}, x\right) * P\left(H_{n}, y\right)=p_{n} * y=x * y=P\left(H_{n}, x * y\right)$. This completes the proof of the lemma.

LEMma 3.4. Let $X$ be as above and let $x, y \in X$, and suppose $\left\{x_{n}\right\},\left\{y_{n}\right\}$ are sequences in $H$ such that $x_{n} \rightarrow x, y_{n} \rightarrow y$. Then there exists $z \in X$ such that $\left\{x_{n} * y_{n}\right\} \rightarrow z$, where $*$ denotes the operation on any $H_{n}$ containing $x_{n}$ and $y_{n}$, and $z$ is independent of the choice of the sequences.

Proof. We distinguish four cases.

Case I. $x=y=1$. From the definition of multiplication on $H$, if $a, b \in P_{k}=\left[\operatorname{Com}\left(1, H \backslash\left\{c_{k}\right\}\right)\right]^{*}$ then $a * b \in P_{k}$. Now $\left\{P_{k}\right\}$ forms a neighborhood basis at the end point 1 . Since both $\left\{x_{n}\right\}$ and $\left\{y_{n}\right\}$ are eventually in each $P_{k},\left\{x_{n} * y_{n}\right\}$ is eventually in each $P_{k}$ and hence $\left\{x_{n} * y_{n}\right\} \rightarrow 1$.

Case II. $x, y$, and 1 all distinct. Let $N$ be an integer so large that $P\left(H_{0}, x\right)$ and $P\left(H_{0}, y\right)$ are in $\operatorname{Com}\left(0, H_{0} \backslash\left\{c_{N}\right\}\right)$ and that the diameter of any component of $X \backslash H_{N}<d(x, y) / 2$. This implies $\operatorname{Com}\left(x, X \backslash H_{N}\right)$ and $\operatorname{Com}\left(y, X \backslash H_{N}\right)$ are disjoint open sets, and we may assume $x_{N} \in \operatorname{Com}\left(x, X / H_{N}\right)$ and $y_{n} \in \operatorname{Com}\left(y, X \backslash H_{N}\right)$ for all $n$. Also we may assume $d\left(x_{n}, y_{n}\right)>d(x, y) / 2$ for all $n$. We now show 
$x_{n} * y_{n}=P\left(H_{N}, y_{n}\right) * P\left(H_{N}, y_{n}\right)$ for all $n$. The statement is obvious if $x_{n}, y_{n} \in H_{N}$. Suppose it is true whenever $x_{n}, y_{n} \in H_{m}$ for some $m \geqq N$, and let $x_{n}, y_{n} \in H_{m+1}=H_{m} \cup Q_{m}$. If $x_{n} \in Q_{m}$ and $y_{n} \in H_{m}$ then $x_{n} * y_{n}=$ $p_{m} * y_{n}$. By hypothesis, since $p_{m}, y_{n} \in H_{m}$ then

$$
p_{m} * y_{n}=P\left(H_{N}, p_{m}\right) * P\left(H_{N}, y_{n}\right) \text {. }
$$

But $P\left(H_{N}, p_{m}\right)=P\left(H_{N}, x_{n}\right)$ since $Q_{m} \subset\left[\operatorname{Com}\left(x_{n}, X \backslash H_{N}\right)\right]^{*}$. Thus $x_{n} * y_{n}=$ $P\left(H_{N}, x_{n}\right) * P\left(H_{N}, y_{n}\right)$. By symmetry the statement is true if $x_{n} \in H_{m}$ and $y_{n} \in Q_{m}$. The statement is obvious if both $x_{n}, y_{n} \in H_{m}$, whereas the case $x_{n}, y_{n} \in Q_{m}$ is impossible for it implies $d\left(x_{n}, y_{n}\right)<d(x, y) / 2<$ $d\left(x_{n}, y_{n}\right)$.

We know $H_{N}$ is a semilattice and hence

$$
x_{n} * y_{n}=P\left(H_{N}, x_{n}\right) * P\left(H_{N}, y_{n}\right) \longrightarrow P\left(H_{N}, x\right) * P\left(H_{N}, y\right)
$$

since $P\left(H_{N}, \cdot\right)$ is continuous.

Case III. $x=y \neq 1$

(a) $x=y \notin H$. Then $x=y$ is an end point of $X$ and $\left\{U_{i}\right\}=$ $\left\{\left[\operatorname{Com}\left(x, X \backslash H_{i}\right)\right]^{*}\right\}$ is a neighborhood basis at $x=y$. We show that if $U_{i}$ is fixed and if $x_{n}, y_{n} \in U_{i} \cap H_{N}$ then $x_{n} * y_{n} \in U_{i} \cap H_{N}$, for any $N$. Note the statement is true for $N \leqq i$. Suppose it is true whenever $x_{n}, y_{n} \in U_{i} \cap H_{m}$ for some $m \geqq i$, and let

$$
x_{n}, y_{n} \in U_{i} \cap H_{m+1}=U_{i} \cap\left(H_{m} \cup Q_{m}\right) .
$$

If $x_{n} \in Q_{m}$ and $y_{n} \in H_{m}$ then $x_{n} * y_{n}=p_{m} * y_{n} \in U_{i} \cap H_{m} \subset U_{i} \cap H_{m+1}$ by the induction hypothesis. By symmetry the statement is true if $x_{n} \in H_{m}$ and $y_{n} \in Q_{m}$. If $x_{n}, y_{n} \in Q_{m}$ then $x_{n} * y_{n} \in Q_{m} \subset U_{i} \cap H_{m+1}$, and if $x_{n}, y_{n} \in H_{m}$ the statement follows from the induction hypothesis.

Since $\left\{x_{n}\right\}$ and $\left\{y_{n}\right\}$ are eventually in each $U_{i}$, and since for each $n$ and each $i$ we can find $N(n, i)$ such that $x_{n}, y_{n} \in U_{i} \cap H_{N(n, i)}$, we conclude that $\left\{x_{n} * y_{n}\right\}$ is eventually in each $U_{i}$. Thus $\left\{x_{n} * y_{n}\right\} \rightarrow x=y$.

(b) $x=y \in H_{N}$, some $N$. Let $\varepsilon>0$. There exists $L>N$ so that the diameter of any component of $X \backslash H_{L}$ is less that $\varepsilon / 2$, and so that $B(x, \varepsilon / 2) \cap P_{L}=\varnothing$. We may assume $d\left(x_{n}, x\right)<\varepsilon / 2$ and $d\left(y_{n}, y\right)<\varepsilon / 2$ for each $n$. Divide $\left\{x_{n} * y_{n}\right\}$ into two (perhaps finite) sequences: If $x_{n} * y_{n} \in H_{L}$ then

$$
\begin{aligned}
x_{n} * y_{n} & =P\left(H_{L}, x_{n} * y_{n}\right) \\
& =P\left(H_{L}, x_{n}\right) * P\left(H_{L}, y_{n}\right) \rightarrow P\left(H_{L}, x\right) * P\left(H_{L}, x\right)=x y=x=y,
\end{aligned}
$$

by Lemma 3.3 and the continuity of multiplication on $H_{L}$. If $x_{n} * y_{n} \notin H_{L}$, then $x_{n} \notin H_{L}$ and $y_{n} \notin H_{L}$ because $B(x, \varepsilon / 2) \cap P_{L}=\varnothing$ and using the definition of multiplication on $H$. Also, using the definition of 
multiplication $x_{n} * y_{n} \in \operatorname{Com}\left(x_{n}, X \backslash H_{L}\right)$ or $x_{n} * y_{n} \in \operatorname{Com}\left(y_{n}, X \backslash H_{L}\right)$. Thus

$$
d\left(x, x_{n} * y_{n}\right) \leqq d\left(x, x_{n}\right)+d\left(x_{n}, x_{n} * y_{n}\right)<\varepsilon
$$

or

$$
d\left(y, x_{n} * y_{n}\right) \leqq d\left(y, y_{n}\right)+d\left(y_{n}, x_{n} * y_{n}\right)<\varepsilon .
$$

In either case $d\left(x, x_{n} * y\right)=d\left(y, x_{n} * y_{n}\right)<\varepsilon$. We conclude that $\left\{x_{n} * y_{n}\right\} \rightarrow$ $x=y$.

Case IV. $y \neq x=1$. We first establish two facts.

(A) If $a, b \in H$ so that $P\left(H_{0}, a\right) \in \operatorname{Com}\left(1, H_{0} \mid\left\{c_{n}\right\}\right)$ and $P\left(H_{0}, b\right) \in$ Com $\left(0, H_{0} \mid\left\{c_{n}\right\}\right)$ for some $n$, then $a^{*} b=P\left(H_{0}, a\right)^{*} b$.

The proof is by the induction on the $H_{i}$ containing $a$. It is clear for $a \in H_{0}$. Suppose the statement is true for $a \in H_{m}, m \geqq 0$, and let $a \in H_{m+1}=H_{m} \cup Q_{m+1}$. Suppose $a \in Q_{m+1}$, for the induction hypothesis assures the statement is true if $a \in H_{m}$. Then since $a$ and $b$ are separated by $c_{m}, b \notin Q_{m+1}$. Hence $a * b=p_{m+1} * b$. But $p_{m+1} * b=P\left(H_{0}, p_{m+1}\right) * b$ by the induction hypothesis, and

$$
P\left(H_{0}, p_{m+1}\right)=P\left(H_{0}, a\right),
$$

so

$$
a * b=P\left(H_{0}, a\right) * b .
$$

Thus (A) is established.

(B) If $a, b \in H$ so that $a \in \operatorname{Com}\left(1, H_{0} \mid\left\{c_{n}\right\}\right)$ and $b \in \operatorname{Com}\left(0, H_{0} \backslash\left\{c_{n}\right\}\right)$ for some $n$, then either $a^{*} b=a^{*} P\left(H_{n}, b\right)$ or $a^{*} b \in \operatorname{Com}\left(b, X \backslash H_{n}\right)^{*}$.

The proof is by induction on the $H_{i}$ containing $b$. If $b \in H_{n}$ then $P\left(H_{n}, b\right)=b$ and the statement is true. Suppose the statement is true when $b \in K_{m}$ for some $m \geqq n$, and let $b \in Q_{m+1}$. If $a \in \operatorname{Com}\left(1, H_{0} \mid\left\{c_{m}\right\}\right)$ then $a * b \in Q_{m+1} \subset \operatorname{Com}\left(b, X \backslash H_{n}\right)^{*}$. If $a \in$ [Com $\left.\left(0, H_{0} \mid\left\{c_{m}\right\}\right)\right]^{*}$ then $a * b=a * p_{m}$. But $a * p_{m}=a * P\left(H_{n}, p_{m}\right)$ by the induction hypothesis, and $P\left(H_{n}, p_{m}\right)=P\left(H_{n}, b\right)$. Thus $a * b=a * P\left(H_{n}, b\right)$ and (B) is established.

We now distinguish two subcases of Case IV.

Subcase 1. $y \in H_{M}$, some $M$. Let $\varepsilon>0$. Choose $M$ so large that $c_{M}$ does not separate $y$ from 0 and the diameter of any component of $X \backslash H_{M}$ is less than $\varepsilon / 2$. We may assume that for each $n$, $P\left(H_{0}, y_{n}\right) \in \operatorname{Com}\left(0, H_{0} \mid\left\{c_{M}\right\}\right)$ and $P\left(H_{0}, x_{n}\right) \in \operatorname{Com}\left(1, H_{0} \mid\left\{c_{m}\right\}\right)$. Then by (A), $x_{n} * y_{n}=P\left(H_{0}, x_{n}\right) * y_{n}$, and by (B), $P\left(H_{0}, x_{n}\right) * y_{n}=P\left(H_{0}, x_{n}\right) * P\left(H_{M}, y_{n}\right)$ or $P\left(H_{0}, x_{n}\right) * y_{n} \in \operatorname{Com}\left(b, X \backslash H_{n}\right)^{*}$. If the former then

$$
x_{n} * y_{n}=P\left(H_{0}, x_{n}\right) * P\left(H_{M}, y_{n}\right) \longrightarrow 1 * P\left(H_{M}, y\right)=y
$$


by the continuity of the multiplication on $H_{M}$ and Lemma 3.3. In the latter case $d\left(P\left(H_{0}, x_{n}\right) * y_{n}, y_{n}\right)<\varepsilon / 2$. We may assume $d\left(y_{n}, y\right)<\varepsilon / 2$, so $d\left(y, P\left(H_{0}, x_{n}\right) * y_{n}\right)<\varepsilon$. Thus we conclude that $\left\{x_{n} * y_{n}\right\} \rightarrow y$.

Subcase 2. $y \notin H$. If $V_{k}=\left[\operatorname{Com}\left(y, X \backslash H_{k}\right)\right]^{*}$ then $\left\{V_{k}\right\}$ is a neighborhood basis, so we need only show $\left\{x_{n} * y_{n}\right\}$ is eventually in each $V_{k}$. Fix a $V_{k}$. We may assume again that for each $n$, $P\left(H_{0}, y_{n}\right) \in \operatorname{Com}\left(0, H_{0} \mid\left\{c_{\mu}\right\}\right), P\left(H_{0}, x_{n}\right) \in \operatorname{Com}\left(1, H_{0} \backslash\left\{c_{\mu}\right\}\right)$, and $y_{n} \in V_{k}$ for some $M \geqq k$. By (A) and (B), $x_{n} * y_{n}=P\left(H_{0}, x_{n}\right) * P\left(H_{M}, y_{n}\right)$ or $x_{n} * y_{n} \in$ $\operatorname{Com}\left(y_{n}, X \backslash H_{\mu}\right)^{*} \subset V_{k}$. However $P\left(H_{M}, y_{n}\right) \in V_{k}$, and $P\left(H_{0}, x_{n}\right) \in H_{0}$, so $P\left(H_{0}, x_{n}\right) * P\left(H_{k}, y_{n}\right) \in V_{k}$. This completes the proof of the lemma.

Theorem 3.5. Let $X$ be a finite dimensional cell-cyclic Peano continnum without a nodal element. Then $X$ admits a semilattice with identity.

Proof. By the above, the dense set $H$ admits a semilattice with identity. For each $x, y \in X$ let $\left\{x_{n}\right\} \rightarrow x,\left\{y_{n}\right\} \rightarrow y$ where $\left\{x_{n}\right\},\left\{y_{n}\right\}$ are sequences in $H$. Define $x y=\lim \left\{x_{n} * y_{n}\right\}$. By 3.4 this limit exists and is independent of the choice of the sequences. It follows that this operation is a semilattice with identity on $X$. Combining this with Theorem 2.3 we have

Corollary 3.6. Let $X$ be a finite dimensional cell-cyclic Peano continuum. Then $X$ admits a commutative semigroup with identity and zero.

CoRollary 3.6. Any retract of a two-cell admits a commutative semigroup with identity.

Proof. Borsuk [1] has shown that a subset $X$ of a two-cell $A$ is a retract of $A$ if and only if $A$ is a locally connected continuum which does not separate the plane. Whyburn [11] has shown that for locally connected continua in the plane, not separating the plane is equivalent to every cyclic element being a simple closed curve with interior, i.e., a two-cell. Thus a retract of a two-cell is a cell-cyclic Peano continuum, and the result follows from Corollary 3.6 .

Definition 3.8. A space $X$ is homogeneous if for each pair of points $x$ and $y$ in $X$ there is a homeomorphism of $X$ onto itself carrying $x$ to $y$.

THEOREM 3.9. Any finite dimensional homogeneous cell-cyclic 
Peano continuum (in particular, any homogeneous retract of a twocell) is a point.

Proof. By a result of Hudson and Mostert [5], any homogeneous compact connected semigroup with identity is a group. Combining this with Corollaries 3.6 and 3.7 , unless $X$ is a point $X$ admits the structure of a group with two idempotents, a contradiction.

\section{REFERENCES}

1. K. Borsuk, Theory of Retracts, Polska Acad. Nauk Monografie Mat., Tom 44 (1967).

2. J. H. Carruth, $A$ note on partially ordered compacta, Pacific J. Math., 24 (1968), 229-231.

3. J. Dugundji, Topology, Allyn and Bacon, 1966.

4. C. A. Eberhart, Some classes of continua related to clan structures, Doctoral Dissertation, Louisiana State University, 1966.

5. A. L. Hudson and P. L. Mostert. A finite dimensional homogeneous clan is a group, Annals of Math., 78 (1963), 41-46.

6. R. J. Koch, Some open questions in topological semigroups, An. Acad. Brasil. Ci., 41 (1969), 19-20.

7. R. J. Koch and L. F. McAuley, Semigroups on continua ruled by arcs, Fund. Math., 56 (1964), 1-8.

8. C. Kuratowski and G. T. Whyburn, Sur les elements cycliques et leurs applications, Fund. Math., 16 (1930), 305-331.

9. J. D. Lawson, Topological semilattices with small semilattices, J. London Math. Soc., (2), 1 (1969), 719-724.

10. G. T. Whyburn, Analytic Topology, Amer. Math. Soc. Colloq. Pub., 28 (1942).

11. Concerning the structure of the continuous curve, Amer. J. Math., 50 (1928), 167-194.

12. W. W. Williams, Semilattices on Peano Continua, Proc. Amer. Math. Soc., 49 (1975), 495-500.

Received November 3, 1975. Portions of this paper generalize unpublished parts of a dissertation presented to the Graduate School of Louisiana State University. The author wishes to thank Professor R. J. Koch for encouraging the work on these results.

UNIVERSITY OF LOUISVILLE

LOUISVILLE, KY 40208 



\section{PACIFIC JOURNAL OF MATHEMATICS}

\section{EDITORS}

RICHARD ARENS (Managing Editor)

University of California

Los Angeles, CA 90024

R. A. BEAUMONT

University of Washington

Seattle, WA 98105

C. C. Moore

University of California

Berkeley, CA 94720

\section{J. DugundJI}

Department of Mathematics

University of Southern California

Los Angeles, CA 90007

R. Finn and J. Milgram

Stanford University

Stanford, CA 94305

\section{ASSOCIATE EDITORS}

\section{E. F. BECKENBACH}

B. H. NEUMANN

F. WoLF

K. YOSHIDA

\section{SUPPORTING INSTITUTIONS}

\author{
UNIVERSITY OF BRITISH COLUMBIA \\ CALIFORNIA INSTITUTE OF TECHNOLOGY \\ UNIVERSITY OF CALIFORNIA \\ MONTANA STATE UNIVERSITY \\ UNIVERSITY OF NEVADA \\ NEW MEXICO STATE UNIVERSITY \\ OREGON STATE UNIVERSITY \\ UNIVERSITY OF OREGON \\ OSAKA UNIVERSITY
}

\author{
UNIVERSITY OF SOUTHERN CALIFORNIA \\ STANFORD UNIVERSITY \\ UNIVERSITY OF HAWAII \\ UNIVERSITY OF TOKYO \\ UNIVERSITY OF UTAH \\ WASHINGTON STATE UNIVERSITY \\ UNIVERSITY OF WASHINGTON \\ AMERICAN MATHEMATICAL SOCIETY
}

The Supporting Institutions listed above contribute to the cost of publication of this Journal, but they are not owners or publishers and have no responsibility for its content or policies.

Mathematical papers intended for publication in the Pacific Jaurnal of Mathematics should be in typed form or offset-reproduced, (not dittoed), double spaced with large margins. Please do not use built up fractions in the text of your manuscript. You may however, use them in the displayed equations. Underline Greek letters in red, German in green, and script in blue. The first paragraph or two must be capable of being used separately as a synopsis of the entire paper. Items of the bibliography should not be cited there unless absolutely necessary, in which case they must be identified by author and Journal, rather than by item number. Manuscripts, in triplicate, may be sent to any one of the editors. Please classify according to the scheme of Math. Reviews, Index to Vol. 39. All other communications should be addressed to the managing editor, or Elaine Barth, University of California, Los Angeles, California, 90024.

The Pacific Journal of Mathematics expects the author's institution to pay page charges, and reserves the right to delay publication for nonpayment of charges in case of financial emergency

100 reprints are provided free for each article, only if page charges have been substantially paid. Additional copies may be obtained at cost in multiples of 50 .

The Pacific Journal of Mathematics is issued monthly as of January 1966. Regular subscription rate: $\$ 7200$ a year (6 Vols., 12 issues). Special rate: $\$ 36.00$ a year to individual members of supporting institutions.

Subscriptions, orders for back numbers, and changes of address should be sent to Pacific Journal of Mathematics, 103 Highland Boulevard, Berkeley, California, 94708.

PUBLISHED BY PACIFIC JOURNAL OF MATHEMATICS, A NON-PROFIT CORPORATION

Printed at Kokusai Bunken Insatsusha (International Academic Printing Co., Ltd.). 8-8, 3-chome, Takadanobaba, Shinjuku-ku, Tokyo 160, Japan.

Copyrit (C) 1975 by Pacific Journal of Mathematics Manufactured and first issued in Japan 


\section{Pacific Journal of Mathematics \\ Vol. 69, No. $2 \quad$ June, 1977}

Carol Alf and Thomas Alfonso O'Connor, Unimodality of the Lévy spectral

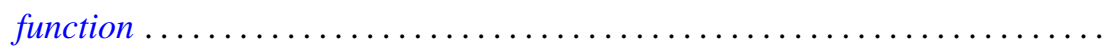

S. J. Bernau and Howard E. Lacey, Bicontractive projections and reordering of

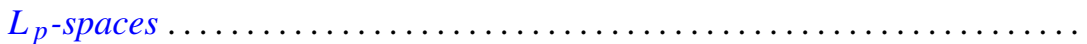

Andrew J. Berner, Products of compact spaces with bi-k and related spaces..... 303

Stephen Richard Bernfeld, The extendability and uniqueness of solutions of ordinary differential equations ...............................

Marilyn Breen, Decompositions for nonclosed planar m-convex sets ..........

Robert F. Brown, Cohomology of homomorphisms of Lie algebras and Lie

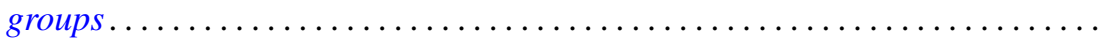

Jack Douglas Bryant and Thomas Francis McCabe, A note on Edelstein's iterative test and spaces of continuous functions ....................

Victor P. Camillo, Modules whose quotients have finite Goldie dimension ....... 333

David Downing and William A. Kirk, A generalization of Caristi's theorem with

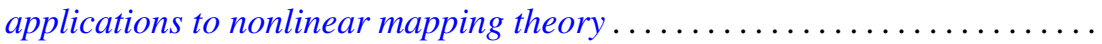

Daniel Reuven Farkas and Robert L. Snider, Noetherian fixed rings ...........

Alessandro Figà-Talamanca, Positive definite functions which vanish at

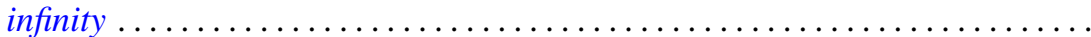

Josip Globevnik, The range of analytic extensions .................. 365

André Goldman, Mesures cylindriques, mesures vectorielles et questions de

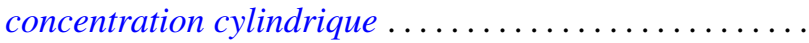

Richard Grassl, Multisectioned partitions of integers..........

Haruo Kitahara and Shinsuke Yorozu, A formula for the normal part of the

Laplace-Beltrami operator on the foliated manifold .... .

Marvin J. Kohn, Summability $R_{r}$ for double series .........

Charles Philip Lanski, Lie ideals and derivations in rings with involution ..

Solomon Leader, A topological characterization of Banach contractions . .

Daniel Francis Xavier O’Reilly, Cobordism classes of fiber bundles . .

James William Pendergrass, The Schur subgroup of the Brauer group . .

Howard Lewis Penn, Inner-outer factorization of functions whose Fourier series

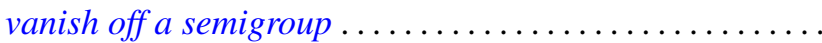

501

William T. Reid, Some results on the Floquet theory for disconjugate definite

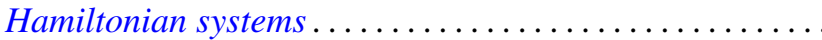

Caroll Vernon Riecke, Complementation in the lattice of convergence

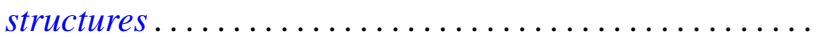

Louis Halle Rowen, Classes of rings torsion-free over their centers ......... 527

Manda Butchi Suryanarayana, A Sobolev space and a Darboux problem ....... 535

Charles Thomas Tucker, II, Riesz homomorphisms and positive linear maps.... 551

William W. Williams, Semigroups with identity on Peano continua ........... 557

Yukinobu Yajima, On spaces which have a closure-preserving cover by finite 